\title{
Understanding the Problem Solving Strategy Based on Cognitive Style as a Tool to Investigate Reflective Thinking Process of Prospective Teacher
}

\author{
Agustan Syamsuddin $^{1, *}$, Dwi Juniati ${ }^{2}$, Tatag Yuli Eko Siswono ${ }^{2}$ \\ ${ }^{1}$ Department of Mathematics Education, Faculty of Teacher Training and Education, Universitas Muhammadiyah Makassar, \\ Indonesia \\ ${ }^{2}$ Department of Mathematics, Universitas Negeri Surabaya, Indonesia
}

Received April 1, 2020; Revised April 27, 2020; Accepted May 27, 2020

Copyright $(2020$ by authors, all rights reserved. Authors agree that this article remains permanently open access under the terms of the Creative Commons Attribution License 4.0 International License

\begin{abstract}
The development of reflective thinking has been a highlight and important in the education of prospective mathematics teachers. It provides them with the opportunities to take a conscious and logical decision on the complex problems they faced. The quality of the problem solving and reflective thinking will differ between one student and another due to their characteristics. This study presents a description of reflective thinking skills of prospective teachers in solving mathematical problems based on the difference in cognitive style. The instruments used in this study consist of (1) GEFT cognitive-style test, (2) a mathematical problem solving task which is a non-routine and open-ended (3) the interview guidelines based on the reflective thinking component. By choosing analysis of qualitative approaches, the data of interviews that are in the form of interview's transcript based on mathematical problem solving results are gathered from two students of prospective mathematics teachers as research participants. One prospective teacher use cognitive field independent style (PTFI) and field dependent style (PTFD). Research findings show that PTFD tends to use the experience to be implemented in mathematical problem solving but PTFD cannot utilize the new information contained, so that PTFD has a reflective-dynamic characteristic. While PTFI tends to use the experience to utilize the new information contained in the problem in order to construct the problem solving strategy so that PTFI has reflective-generative characteristic. It is indicated that there are differences in the characteristics of reflective thinking process among prospective teachers based on difference of cognitive style.
\end{abstract}

Keywords Cognitive Style, Problem Solving, Prospective Teacher, Reflective Thinking

\section{Introduction}

One of the objectives that must be achieved in mathematics learning for the prospective teachers' students is possessing problem solving skills and able to apply logical, critical, systematic and innovative thinking in the context of development or implementation of science and/or technology in accordance with the field of expertise. It is contained in the regulation of the Minister of Research, Technology and higher Education of the Republic of Indonesia number 44 year 2015. Regarding the thinking abilities, Demirel et al. [1] revealed that one of the thinking skills needed to be enhanced in mathematics learning is a reflective thinking skill where the development of reflective thinking is the center of mathematics Education. This statement shows that the development of reflective thinking has been a highlight and important in mathematics education, especially in the education of prospective mathematics teachers. It can underlie the importance of knowing the reflective thinking in the education of prospective mathematics teachers.

Therefore, reflective thinking skills become one of the most prominent issues on education of teacher profession [2-4]. This skill can be applied in learning to solve mathematics problem since it can bring out the curiosity of students [5]. In addition, this reflective thinking skill provides students with the opportunity to take a conscious and logical decision on the complex problems they faced [6]. Further, it helps someone in forming concepts and abstractions and also developing new concepts that ultimately result the solution of the problem given [7]. This indicates that reflective thinking can be identified through the process of problem solving of prospective teachers in using mathematical concepts and knowledge to find a solution of the problems. This was emphasized by 
Jonassen [8] and McGregor [9] that the process of problem-solving is the process of implementing all the knowledge in both new and unusual situations. Thus, the quality of the problem solving will differ between one student and another due to their characteristics.

One of the factors affecting the problem solving process is cognitive style [10]. Saracho [10] states that cognitive styling is a characteristic in the thought process that is consistent and reflected in individuals when the individual processes the information. In addition, Riding et al., [11] state that cognitive styles refer to individual tendencies and consistencies in understanding, remembering and organizing, thinking and solving problem. The difference in cognitive style is indicated to affect students' ability in reflective thinking and mathematical problem solving. This assumption is emphasized by the opinion of Bodine [12] that cognitive style has a correlation with intellectual and perception behavior. Intellectual is related to a person's ability to think, while the perception is related to someone's ability to perceive or interpret something.

The cognitive style studies in this study focused on cognitive styles developed by Witkin et al., [13] namely field-independent and field-dependent cognitive styles. Field-independent individuals tend to have analytical characters, choosing a response based on a situation that occurs, resulting in a perception that is only partially influenced by a change in situation. Further, Witkin et al., [13] revealed that field-dependent individuals are prone to meet difficulty in facing different situations so that there is a perceived sense of perception influenced by changes situations that occur. Hence, it can be argued that individuals who have field-independent cognitive style have a tendency to respond to situations based on their views that are analytic, while individuals with field-dependent cognitive styles have a tendency to respond the situations based on the situation they face.

With the difference in cognitive style, it is possible that students solve problems by responding to the problem based on the perception they have, therefore in order to identify the reflective thinking skills of prospective teachers, the process of solving mathematical problems conducted by prospective teachers based on cognitive style can be used. Hence, the author considers that it is necessary to know the ability of reflective thinking students in the mathematics problem solving by also considering the elements of the student's cognitive style in this case, the cognitive style of the field independent and field dependent they have. By paying attention to this aspect, an overview of the impact of cognitive-style differences on the reflective thinking skills of the prospective teachers in mathematics problem solving will be obtained. Thus, in this paper the author aims to provide answers of research question: How is the impact of cognitive-style differences on the reflective thinking process of prospective teachers in solving mathematical problems?

\section{Research Methods}

Based on the research question as a starting point outlined in the introduction, a descriptive study with a qualitative approach analysis is chosen in order to answer the question $[14,15]$ with the design type as a case study $[16,17]$. This is in line with the purpose of research that intends to deeply describe the meaning of phenomenon (reflective thinking process of prospective teacher's students in solving mathematical problems based on dimensions or differences in cognitive style) and object characteristics of the case studied are limited [16] which are two students of prospective mathematics teachers at Universitas Muhammadiyah Makassar, Indonesia, who were selected as the subjects in this study. Each of the prospective teacher with field-independent style (PTFI) and field-dependent style (PTFD).

The instruments used in this study consist of (1) GEFT cognitive-style test instruments developed by Witkin, et al., [13] consisting of 25 items using the criteria of Kepner and Neimark [18]. If the subject gets $0 \leq$ the score $\leq 9$ then it categorized as the dependent field. Furthermore, if the subject gets $10 \leq$ the score $\leq 18$ it is classified as an independent field; (2) a mathematical problem solving task sheet used in the study is a non-routine and open-ended mathematical issue designed to acquire data related to student problem-solving strategies using reflective thinking skills (3) the interview guidelines, which are used to collect data through interviews to research subjects in a directed way. The questions asked refer to the process of reflective thinking according to the study [19]. The aspects of the reflective thinking components are examined in the study adapted from Dewey [20], Lee [21], Rodgers [22] and Zehavi and Mann [23] which are detailed in the following Table 1. 
Table 1. A Reflective Thinking Process Descriptor in Solving Mathematical Problems

\begin{tabular}{|l|l|}
\hline \multicolumn{1}{|c|}{ Reflective Thinking Stages } & \multicolumn{1}{c|}{ Descriptor } \\
\hline $\begin{array}{l}\text { Description of problem based on the } \\
\text { experience }\end{array}$ & $\begin{array}{l}\text { The process of describing or formulate problems using the knowledge and previous } \\
\text { experiences possessed and associating the information explicitly stated in the problem }\end{array}$ \\
\hline $\begin{array}{l}\text { Elaboration of the concepts in } \\
\text { generating solution process based on the } \\
\text { experience }\end{array}$ & $\begin{array}{l}\text { The process of elaborating concepts in order to produce ideas to form problem-solving } \\
\text { strategies by using the knowledge and previous experiences owned and associating those } \\
\text { ideas to build solution strategies }\end{array}$ \\
\hline $\begin{array}{l}\text { Analysis of solution by using insight } \\
\text { based on the experience }\end{array}$ & $\begin{array}{l}\text { Analyzing the completion strategies undertaken using knowledge and previous learning } \\
\text { experiences and considering the relevance of experience with information from the problem } \\
\text { purpose related to the problem solving }\end{array}$ \\
\hline $\begin{array}{l}\text { Evaluating selected solution based on } \\
\text { the experience }\end{array}$ & $\begin{array}{l}\text { Evaluate the solutions that have been conducted by associating previous knowledge and } \\
\text { experiences to acquire a conclusion that is more believed to be true }\end{array}$ \\
\hline
\end{tabular}

To analyze the research data that has been collected, a research analysis was used with qualitative approach of research that produces descriptive data, namely speech or writings and behaviors that can be observed from the subject itself. Before being analyzed, the data credibility is examined using time triangulation and member-check [24] [25]. In this case, the interview transcript data of the problem solving tasks in two stages of triangulation is used to determine the data credibility, hence the valid data obtained.

\section{Results}

In this section, the results obtained from the subjects of reflective thinking in solving mathematical problems will be described as follows.

\subsection{Reflective Thinking Process with Field-Independent Cognitive Style of Prospective Teacher's Students (PTFI) in Solving Mathematics Problem}

In the stage of description of problem based on the experience, PTFI reformulates the problem by using its own sentence in accordance with the order of information contained in the problem based on the knowledge invaded. PTFI identifies that the problem is related to the concept of geometry and algebraic counting operations. If associated with experience and knowledge, the problems faced by PTFI are related to linear programs as it requires the concept of multiplication, addition, division and subtraction, two-variable linear equations and inequalities, algebra, geometry. Further, the difficulties faced by PTFI when solving problems are related to the skills of making mathematical models, drawing, use of operations and strategies in solving problems. While, based on experience or knowledge, PTFI has difficulty in using operations and mathematical models.

In the stage of elaboration of the concepts in generating solution process based on the experience, PTFI identifies the two concepts needed to solve a problem namely the concept of the operation of algebraic and geometry. PTFI tends to use good drawing strategies on both current and previous issues. PTFI explains the difficulties faced when implementing a strategy which are related to inaccuracy and less concentration due to time constraints when solving problems. For them, the completion strategy could be developed by adapting or modifying the previous strategy. Regarding the development of the completion strategy, PTFI has expressed positive impacts (facilitating completion) and negative (time consuming). PTFI explains that a drawing strategy is a more effective strategy and makes it easy to check solutions and easily associate answers with problems.

In the stage of analysis of solution by using insight based on the experience, PTFI identifies 2 (two) excellent problem solving criteria that is problem solving done in a sequence (step by step); and accuracy of understanding problems. PTFI identifies 4 (four) aspects for effective problem solving; namely (a) understand the meaning of each word; (b) create a mathematical model; (c) perform mathematical calculations; (d) interpret the results obtained with the context of the problem. PTFI identifies two strengths (the completion of more than one way and the drawing strategy) and two shortcomings (less thorough and concentration) related to the problem solving. PTFI fixes the weakness by multiplying the practice of doing test or other problems.

For the stage of evaluating selected solution based on the experience, PTFI chooses the completion procedure by drawing as it facilitates and convinces the PTFI to obtain the correct answer. PTFI discloses the procedure used in accordance with the principles and rules of mathematical operations which (1) record all the known information contained in the problem; (2) record what is asked of the question; (3) perform the completion stage of the mathematical problems he faced; (4) re-check both the process and the result of the answer obtained, whether it is in accordance with the purpose of the problem. To find out whether the solutions have answered the problems, PTFI checks several times of the completion in several ways, which is resulting in varying answers. To test internal consistency or errors in the operation or procedure of problem solving, PTFI checks the completion associated with the operations used. The subject reassures itself by interpreting the results of the breakdown gained into the context of the presented problem. 


\subsection{Reflective Thinking Process with Field-Dependent Cognitive Style of Prospective Teacher's Students (PTFD) in Solving Mathematics Problem}

At the stage of description of problem based on the experience, PTFD describes problems with their own sentences on an irregular basis based on the order of information contained in the problem. PTFD identifies that problems are related to the concept of the algebraic counting operation. If associated with experience or knowledge, the problems faced by the PTFD are related to measurement. The difficulties faced by PTFD when solving problems are related to problem solving strategies. Meanwhile, based on experience or knowledge, the difficulty of the subject is associated with unchastity to transform from one form to another.

For the stage of the elaboration of the concepts in generating solution process based on the experience, PTFD proposed one concept required (algebraic calculate operations related to summation, subtraction, multiplication and division) to solve the problem. PTFD solves the problem with a "reading to understand the problem" strategy because it makes it easier and also the easiest to be understood. PTFD explained the difficulties of implementing a strategy related to the "workaround" due to the PTFD idea of changing its context to facilitate the completion process of the problems he faced. PTFD explains that there is a tendency to implement the same strategy when facing the problem of "reading to understand".

While at the stage of analysis of solution by using insight based on the experience, PTFD identified 4 (four) excellent problem solving criteria namely; (a) understand the problem; (b) determine what is known and asked; (c) choose the concept of completion; (d) perform a re-check. PTFD mentions the advantages related to the problem solving that has been done by two different answers so that he or she can do the consideration and compare the two answers to choose the answer that tends to be correct. MPFD identifies strengths (two different answers) and deficiencies (answers are ambiguous) and seeks to improve the deficiency by improving precision, choosing the right concept and the skills of making mathematical models.

In the evaluating stage of selected solution based on the experience, PTFD chose the "read to understand" procedure to make it easier for MPFD to believe the answers gained tend to be true. Furthermore, to find out the answers that have been answered, PTFD checks the answers obtained by selecting the most appropriate answer by recounting and checking the suitability between the problems solved with the concepts used. PTFD explains that to test for errors in the operation or procedure of problem solving, PTFD checks all the information used and adjusted to the purpose of the problem.

\section{Discussion}

The key findings in this study are the themes compiled from the codes generated in the process of the data-processing [26]. The category is based on the descriptor of the reflective thought process in solving the problem as a guide in identifying the required research data (see table 1.). This research finally provides a description or overview of the reflective thinking of prospective teachers' students in solving mathematical problems based on cognitive style. The results of these studies have shown that both the PTFI and PTFD subjects meet all of the reflective thinking components that can be explained as follows.

\subsection{Description of Problem Based on the Experience}

In this activity, the subject performs an orientation towards the problem. Based on their knowledge, the subject understands the problem by describing and reformulating the problem using his own language. The subject presents all the information contained on the problem completely and identifies mathematical facts such as concepts, traits and principles related to the problem. In addition, the subject gathers new facts based on the learning experiences that are concepts, mathematical traits and problems that have been found before. Afterwards, synthesize ideas are used to choose the concepts that are related and relevant to the problems faced.

This is in line with the results of the study conducted by King and Kitchener [26] stating that reflective thinking helps someone in solving complex problems, because reflective thinking helps someone in identifying concepts, facts, formulas, and theories relevant to the solution of the identified problems. In this activity, both subjects describe the problem differently. If the PTFI performs in a sequence way, the PTFD performs in a randomized manner which is not based on the order of the problems presented. This indicates that PTFD tends to be neat and structured when conveying information while PTFD tends to be random and unorganized when it comes to ideas related to the information they acquire.

This is in accordance with the results of the study of Witkin et al., [13] who found that individuals with cognitive field independent style tend to be orderly and organized whilst individuals with cognitive field dependent style tend to be irregular.

\subsection{Elaboration of the Concepts in Generating Solution Process Based on the Experience}

At this stage, the subject specifically analyzes the concepts or principles and linkages of the concepts or principles contained in the problem presented. This is in accordance with the findings of research conducted by 
Sezer [27] stating that reflective students become aware and actively assess what he or she knows, what he or she should know and how he connects one concept with other concepts. Furthermore, the subject identifies the concept needed to solve the problem. This indicates there is a sense of curiosity in the subject when responding to problems presented to them.

This statement is supported by Ortiz [28] stating that one of the important things when reflective thinking is curiosity, is that curiosity will explain the phenomena that require answers clearly and the desire to seek their own answers to the issues raised. In addition, the findings are also supported by the study conducted by Betne [29] stating that reflective thinking is a tool for developing students' ability to use mathematical concepts.

Moreover, the subject explains how to choose the appropriate operations and strategies in solving the presented problems. It is supported by Mcduffie statement [30] that the important thing on reflective thinking is the act as a tool that promotes thinkers during situations of solving problems since reflective thinking provides an opportunity to think in choosing the right strategy to achieve the goal of the problem.

Further, the subject explains the difficulties faced when implementing a chosen strategy when solving problems based on the knowledge and experience he have. Then, the subject explains how to adapt the approach or strategy used to solve problems with other problems and its impact. This statement is supported by the findings of Diana [31] that one of the important attributes of reflective thought is the ability to modify thinking and action for improvement on the next or upcoming problem.

This indicates that it takes a thought to modify and develop a problem solving strategy so that the problem solving strategy can be used when solving other problems in the future or more complex problems [19]. The statement is in line with the results of the research conducted by Song et al., [7] stating that reflective thinking on problem solving helps a person in forming concepts and abstractions and developing new concepts that ultimately result in a solution of the given problem.

The activity done by the subject is that PTFD tries to implement a strategy to solve the problem by trying to change the context of the question. This is conducted because PTFD has difficulty in resolving problems. PTFD is unable to implement the concept of the algebraic counting operation because it focuses on the questions posed on the problem. This indicates that the PTFD cannot maximally utilize the new information contained in the problem to resolve the problem.

While PTFI, trying to use a drawing strategy to try to solve the problem after facing difficulties in implementing the required concepts which are the operation of algebraic and geometry counting. Thus, PTFI tried to apply all the knowledge he had based on his experience in the new situation or problem he faced. In addition, PTFI uses the new information contained in the problem and uses it to solve the problem by giving an explanation through the image as an illustration of the completion.

\subsection{Analysis of Solution by Using Insight Based on the Experience}

The subject describes how to determine the appropriate solution criteria. In this activity, the subject identifies the criteria of proper resolution based on the knowledge and experience that is possessed by the subject. This indicates that the subject involves a critical assumption of the problem solving. The statement complies with the results of the research of Kember [32] stating that reflective thinking involves a critical assumption of the content or problem resolution process. The subject explains the advantages and disadvantages of the solution and explains how the efforts to improve the weaknesses are owned or performed when solving the problem.

This activity indicated that with reflective thinking, the subject sought to convey the constriction of reflective thinking towards the completion of the subject. It is supported by the statement of Hsieh [33] that strategies or ways with reflective thinking have a positive impact on improving student learning performance achievements, where reflective thinking can be used as a creative way to intensify student involvement in the mathematical problem-solving process.

\subsection{Evaluating Selected Solution Based on the Experience}

The subject describes how to decide which procedures or operations to use at the time of problem solving. This activity corresponds to the findings of Gurol [34] who states that reflective thinking as a process of directional and precise activities where individuals are aware to analyse, evaluate, motivate, gain profound meaning, use the right strategy in resolving a problem. Thus, the subject can decide on the exact strategy used in the problem solving. Further, the subject explains whether the solution or the answers obtained answered the problem presented. It is explained that the subject clarifies the completion done by the subject. This statement is supported by the results of the research conducted by Henderson [35] stating that reflective thinking involves analyzing, comparing, synthesizing, clarifying, and choosing what one does show the reflection activity itself.

Moreover, the subject describes how to test internal consistency or errors in the operation or solution from the problem solving. This is in accordance with the results of research conducted by Ambrose [36] and Gelter [37], stating that reflective thinking has been identified that it can give learners the opportunity to justify misconceptions by helping students to think what he is doing and why he is doing it. Hence, the subject can be more confident with 
the answers obtained which are likely to be correct [38-40].

From several explanations above, it can be suggested that prospective teachers with cognitive field dependent style (PTFD) based on the experience and knowledge he has, has a tendency of not being able to maximally utilize new information of problem. He only focused on the main problem raised from the math problem so he had a hard time solving the problems although he was able to apply all the knowledge and experience he had to the situation or problem he faced. This indicates that the PTFD has dynamic reflective thinking characteristics that can also be called reflective-dynamic where the PTFD uses his experience and knowledge to be applied in the problem solving process which is unusual as he did before.

While a prospective teacher with cognitive field independent style (PTFI), when thinking reflective, used the knowledge and experience he had in solving such mathematical problems with a tendency in trying to use optional strategies. He used another strategy, when he had a deadlock to solve the problem by using the algebraic equation strategy. In this case the strategy used is drawing. PTFI tries to solve the problem with the strategy after difficulties in implementing the required concepts.

It is therefore PTFI tried to apply all the knowledge he had based on his experience in the new situation or problem he faced. In addition, PTFI uses the new information contained in the problem and uses it to solve the problem by giving an explanation through the image as an illustration of the completion. Hence, PTFI has a generative reflective thinking characteristic that can be termed as reflective-generative where PTFI uses the experience and knowledge he has in order to use the new information in the presented problems and utilizes the information to construct a completion strategy as an explanation of the solution he acquired.

\section{Conclusions}

The results of this study gives an idea that the quality of the reflective thinking process in solving mathematical problems differs between individuals caused by characteristic differences in this case the cognitive style adopted by the individual. The cognitive individual filed dependent style tends to be dynamic where this individual uses his experience and knowledge to be applied in the process of solving such unusual mathematical problems as the completion he had done before. However, the students was unable to utilize the new information contained in the problem and only focused on the main problem presented so that this individual has a dynamic-reflective thinking characteristic.

While independent cognitive-styled individuals tend to be generative in which the individual uses the experience and knowledge he or she has to exploit the new information contained in the problem presented in order to construct alternative completion strategies after experiencing a deadlock as an explanation of the solutions he or she acquired. Thus, this individual has a characteristic reflective thinking that is generative that we can term as reflective-generative.

However, the most important thing about reflective thinking is to encourage prospective mathematics teacher's students in solving the complex mathematical problems situations since it gives them the opportunity to think about how he actually solves problems and how to set up a problem solving strategy in order to achieve the objectives. Hence, reflective thinking can bridge a person to be able to solve problems that affect the mastery of mathematical concepts well.

\section{REFERENCES}

[1] Demirel, M., Derman, I. and Karagedik, E. A study on the relationship between reflective thinking skills towards problem solving and attitudes towards mathematics. Procedia-Social and Behavioral Sciences, Vol. 197, 2086-2096, 2015.

[2] Lee, H. J. Understanding and assessing preservice teachers' reflective thinking. Teaching and teacher education, Vol. 21, No. 6, 699-715, 2005.

[3] Lim, L. A. Y. L. A comparison of students' reflective thinking across different years in a problem-based learning environment. Instructional Science, Vol. 39, No. 2, 171-188, 2011.

[4] Syamsuddin, A. Analysis of prospective teacher's mathematical problem solving based on taxonomy of reflective thinking. Journal of Physics: Conference Series, Vol. 1157, No. 3, 032078, 2019.

[5] Lipman, M. Thinking in education. Cambridge University Press, 2003.

[6] Choy, S. C., \& San Oo, P. Reflective thinking and teaching practices: A precursor for incorporating critical thinking into the classroom?. International journal of Instruction, Vol.5, No. 1, 167-182, 2012.

[7] Song, H. D., Grabowski, B. L., Koszalka, T. A., \& Harkness, W. L., Patterns of instructional-design factors prompting reflective thinking in middle-school and college level problem-based learning environments. Instructional Science, Vol. 34, No. 1, 63-87, 2006.

[8] Jonassen, D. H., Learning to solve problems: An instructional design guide (Vol. 6). John Wiley \& Sons, 2004.

[9] McGregor, D. Developing thinking; developing learning. McGraw-Hill Education: UK, 2007.

[10] Saracho, O., Matching teachers' and students' cognitive styles. Early Child Development and Care, Vol. 173, No. 2-3, 161-173, 2003.

[11] Riding, R. J., Glass, A., \& Douglas, G., Individual 
differences in thinking: Cognitive and neurophysiological perspectives. Educational Psychology, Vol. 13, No. 3-4, 267-279, 1993.

[12] Bodine, R., L., The effect cognitive style, task structure and task setting on student's outcome-cognitve and affective. The American Educational Research Association (4), New York, 1977.

[13] Witkin, H. A., Moore, C. A., Goodenough, D. R., \& Cox, P. W., Field - dependent and field - independent cognitive styles and their educational implications. ETS Research Bulletin Series, Vol. 1975, No. 2, 1-64 1975.

[14] Creswell, J.W., Research design qualitative, quantitative, and mixed methods approaches. third edition. California: Sage Publication, 2010.

[15] Lodico, M. G., Spaulding, D. T., \& Voegtle, K. H., Methods in educational research: From theory to practice (Vol. 28). John Wiley \& Sons, 2010.

[16] Merriam, S. B., \& Tisdell, E. J., Qualitative research: A guide to design and implementation. John Wiley \& Sons, 2015.

[17] Creswell, J. W., \& Poth, C. N., Qualitative inquiry and research design: Choosing among five approaches. Sage publications, 2016

[18] Kepner, M. D., \& Neimark, E. D., Test-retest reliability and differential patterns of score change on the Group Embedded Figures Test. Journal of Personality and Social Psychology, Vol. 46, No. 6, 1405-1413, 1984.

[19] Agustan, S., Juniati, D., \& Siswono, T. Y. E., Reflective thinking in solving an algebra problem: a case study of field independent-prospective teacher. Journal of Physics: Conference Series, Vol. 893, No. 1, 012002, 2017.

[20] Dewey, J., How We Think. A restatement of the relation of reflective thinking to the educative process, DC Heath and Company, Boston etc., 1933.

[21] Lee, I. Fostering preservice reflection through response journals. Teacher Education Quarterly, Vol. 35, No. 1, 117-139, 2008.

[22] Rodgers, C., Defining reflection: Another look at John Dewey and reflective thinking. Teachers college record, Vol. 104, No. 4, 842-866, 2002.

[23] Zehavi, N., \& Mann, G., Instrumented techniques and reflective thinking in analytic geometry. The Mathematics Enthusiast, Vol. 2, No. 2, 83-92, 2005.

[24] Flick, U., An introduction to qualitative research. Sage Publications Limited, 2018.

[25] Mathison, S., Why triangulate?. Educational researcher, Vol. 17, No. 2, 13-17, 1988.

[26] King, P. M., \& Kitchener, K. S., Reflective judgment model. New Directions for Student Services, Vol. 88, 41-50, 1999.

[27] Sezer, R., Effects of reflective writing in mathematics methods courses on pre-service teachers' perceptions. Eurasian Journal of Educational Research (EJER), Vol. 40, 2010.
[28] Ortiz, C. M. A., Does philosophy improve critical thinking skills?. University of Melbourne, Department of Philosophy, Australia, 2007.

[29] Betne, P. Reflection as a learning tool in mathematics. Transit: The LaGuardia Journal on Teaching and Learning, Vol. 4, 93-101, 2009.

[30] McDuffie, A. R., Mathematics teaching as a deliberate practice: An investigation of elementary pre-service teachers' reflective thinking during student teaching. Journal of mathematics teacher education, Vol. 7, No. 1, 33-61, 2004.

[31] Diana, L., Assesing secondary students' reflective thinking in project work. Journal of singapura examination and assessment board, Vol. 71, 133-149, 2009.

[32] Kember, D., Determining the level of reflective thinking from students' written journals using a coding scheme based on the work of Mezirow. International journal of lifelong education, Vol. 18, No. 1, 18-30, 1999.

[33] Hsieh, P. H., \& Chen, N. S., Effects of reflective thinking in the process of designing software on students' learning performances. Turkish Online Journal of Educational Technology-TOJET, Vol. 11, No. 2, 88-99, 2012.

[34] Gurol, A., Determining the reflective thinking skills of pre-service teachers in learning and teaching process. Energy Education Science and Technology Part B: Social and Educational Studies, Vol. 3, No. 3, 387-402, 2011.

[35] Henderson, K., Napan, K., \& Monteiro, S., Encouraging reflective learning: An online challenge. In Beyond the comfort zone: Proceedings of the 21st ASCILITE Conference, 357-364, 2004.

[36] Ambrose, R., Initiating change in prospective elementary school teachers' orientations to mathematics teaching by building on beliefs. Journal of Mathematics Teacher Education, Vol. 7, No. 2, 91-119, 2004.

[37] Gelter, H., Why is reflective thinking uncommon. Reflective practice, Vol. 4, No. 3, 337-344, 2003.

[38] Agustan, S., Juniati, D., \& Siswono, T. Y. E.. Profile of male-field dependent (FD) prospective teacher's reflective thinking in solving contextual mathematical problem. American Institute of Physics Conference Series, Vol. 1867, No. 2, 020034, 2017.

[39] Agustan, S., Juniati, D., \& Siswono, T. Y. E. Investigating and analyzing prospective teacher's reflective thinking in solving mathematical problem: A case study of female-field dependent (FD) prospective teacher. American Institute of Physics Conference Series, Vol. 1848, No. 4, 040018, 2017.

[40] Syamsuddin, A. Describing taxonomy of reflective thinking for field dependent-prospective mathematics teacher in solving mathematics problem. International Journal of Scientific \& Technology Research, Vol. 9, Issue 3, 4418-4421, 2020. 